\title{
Revised Record of Decision for the Electrical Interconnection of the Summit/Westward Project
}

\section{INTRODUCTION}

The Bonneville Power Administration (BPA) has decided to amend its July 25, 2003, Record of Decision (ROD) regarding the proposed Summit/Westward Project (Project) to offer contract terms for an optional interconnection of this Project into the Federal Columbia River Transmission System (FCRTS). Under this optional interconnection plan, BPA would integrate electric power from the Project into the FCRTS at a point adjacent to Clatskanie People's Utility District (CPUD) existing Wauna Substation. In order to deliver power to this location, CPUD would develop a new substation (Bradbury Substation) at a site near the Project and a new 230-kV transmission line from there to CPUD's Wauna Substation, which is already connected to the FCRTS. As part of this revised decision, BPA will facilitate CPUD development of the Bradbury-Wauna transmission line by allowing joint use of BPA right-of-way. This will involve reconstructing a section of BPA's 115-kV Allston-Astoria No. 1 transmission line from singlecircuit $\mathrm{H}$-frame wood-pole design to double-circuit single metal pole design. Terms of BPA participation in CPUD's development of the Bradbury-Wauna transmission line will be documented in a Construction Agreement. This optional interconnection plan is in addition to BPA's previous offer for interconnection of the Project at BPA's Allston Substation, as documented in the July 25,2003 , ROD.

As with the initial interconnection plan, the decision to offer terms to interconnect the Project through the optional interconnection plan is consistent with BPA's Business Plan Final Environmental Impact Statement (BP EIS) (DOE/EIS-0183, June 1995), and the Business Plan Record of Decision (BP ROD, August 1995). This decision thus is similarly tiered to the Business Plan ROD.

\section{BACKGROUND}

BPA's initial decision to offer terms for interconnection of the proposed Summit/Westward Project at BPA's Allston Substation is documented in a ROD dated July 25, 2003. ${ }^{1}$ This initial decision was consistent with the Final Order and Site Certificate issued to Westward Energy, LLC, for the Project by the Oregon Energy Facility Siting Council (EFSC) on October 3, 2002, that specified interconnection of the Project at Allston Substation. However, as recognized in the initial ROD, on July 10, 2003, Westward Energy requested EFSC to amend the Site Certificate by including an option for interconnection of the Project. Amendment \#1 to the Site Certificate "adds an option of a transmission line alternative to allow for connection between the Summit Project site and a new substation (the 'Bradbury Substation')." EFSC approved the requested Site Certificate amendment on February 13, 2004. Westward Energy subsequently requested BPA generation interconnection services with BPA's point of receipt at a point near CPUD's Wauna Substation. Consistent with BPA's Open Access Transmission Tariff for the FCRTS, BPA needs to respond to this request.

\footnotetext{
${ }^{1}$ A full description of the initial interconnection plan and its potential environmental effects is contained in BPA's initial ROD for the Project.
} 


\section{OPTIONAL GENERATION INTERCONNECTION PLAN}

The initial plan for generation interconnection of the Summit/Westward Project at Allston Substation involves using a new 230-kV transmission line that Portland General Electric (PGE) is planning to construct and operate, primarily to serve its own generation project near the Summit/Westward Project site. The optional plan will use new transmission facilities that CPUD has been planning to construct to serve increasing loads in the Port Westward Industrial Park and also to reinforce its system. Specifically, Westward Energy would construct and operate an approximately 300-foot-long transmission line from the Project site to a new Bradbury Substation that would be constructed by CPUD near the Summit/Westward Project site. CPUD also would build a new 230-kV transmission line from there about 17 miles west to CPUD's existing Wauna Substation. Owned and operated by CPUD, Wauna Substation is already connected to the FCRTS. From the Bradbury Substation, CPUD's new Bradbury-Wauna 230-kV transmission line would extend about 9 miles southwest to a point along BPA's existing 115-kV Allston-Astoria No. 1 transmission line. From there, about 8 miles of BPA's Allston-Astoria No. 1 transmission line would be rebuilt from its current single-circuit $\mathrm{H}$-frame wood-pole design to a new double-circuit single metal pole design to accommodate a section of the CPUD's new Bradbury-Wauna 230-kV transmission line. This partial rebuild has the advantage of using existing transmission line right-of-way and access roads rather than creating new, additional right-of-way and access roads. Where the Allston-Astoria No. 1 transmission line corridor passes south of Wauna Substation, the new transmission would turn north along vacant BPA right-of-way adjacent to BPA's 230-kV Wauna Tap to Allston-Astoria, a distance of about 1800feet.

\section{PUBLIC PROCESS AND CONSIDERATION OF COMMENTS}

Consistent with BPA's strategy for tiering appropriate subsequent decisions to the BP ROD, a public process conducted for the Site Certificate amendment provided opportunities for public comment. In reviewing the requested amendment, the Oregon Department of Energy

(Department) identified potentially affected agencies, local governments, and Tribes, and on July 10, 2003, mailed a copy with a request for comment to:

Department of Geology and Mineral

Industries

Department of Fish and Wildlife

Division of State Lands

Department of Agriculture

Water Resources Department

Department of Parks and Recreation

State Historic Preservation Department

Department of Environmental Quality

Department of State Fire Marshall

Public Utilities Commission

Building Codes Division

Department of Forestry

Northwest Power and Conservation Council
Department of Transportation

Dept. of Land Conservation \& Development

Department of Aviation

City of Astoria

City of Rainier

City of Saint Helens

City of Clatskanie

City of Columbia City

Columbia County

Confederated Tribes of the Grand Ronde

Clatsop County

Confederated Tribes of the Warm Springs

Chinook Indian Tribe

Confederated Tribes of the Siletz 
The Department also mailed the requested amendment and request for comment to their general mailing list.

The Department received four comments on the requested amendment. First, the Department of State Lands expressed concern that CPUD may need a removal/fill permit because of wetlands at the Bradbury Substation site; more specific information about the site location resolved this concern. The Columbia County Department of Land Development Services noted that the County would likely approve a conditional use permit for Bradbury Substation and the section of transmission line within Columbia County. The Clatsop County Department of Community Development commented that the section of the transmission line in Clatsop County is an allowed use under applicable Clatsop County Zoning Ordinance requirements and standards. Finally, one comment from an individual expressed support based on the benefits of cooperation between Westward Energy and CPUD.

On January 2, 2004, the Department issued a proposed order approving the requested Site Certificate amendment and, with distribution as before, again requested comment. The Department received no comments on the proposed order. On February 13, 2004, at its regular Council meeting open to the public, EFSC found the requested amendment consistent with applicable statutes, rules, and statewide land use planning goals, with no significant adverse impact to public health and safety or the environment, and approved the amendment.

\section{ENVIRONMENTAL ANALYSIS AND MITIGATION}

As discussed in the initial ROD for the Project, the BP EIS was reviewed to determine whether offering terms to interconnect the Project is adequately covered within its scope. Based on this review, it was determined that the Project clearly falls within the scope of the BP EIS. The following describes the site-specific impacts associated with the optional interconnection plan. ${ }^{2}$

\section{$\underline{\text { Soils }}$}

Rebuilding a section of BPA's 115-kV Allston-Astoria No. 1 line to 230-kV double circuit design, including improvement of existing access roads, could potentially increase erosion during construction. Afterwards, erosion would likely diminish as disturbed sites revegetate or otherwise stabilize. In the long-term, erosion would return to pre-construction rates.

Mitigation:

- Existing structures within 50 feet of waterways will be cut at the ground surface rather than 2 feet below the ground surface to minimize soil disturbance.

- Structures will be located away from nearby streams and wetlands.

- Drainage improvements will be properly sized.

- Construction will be performed as much as possible during dry season when stream flow, rainfall, and runoff are low.

\footnotetext{
${ }^{2}$ Environmental and other information concerning the proposed Summit/Westward Project itself is contained in the Initial ROD for the Project.
} 
- In disturbed areas, erosion control measures such as silt fencing, straw mulch, and straw bale check dams will be used.

- Vegetative buffers will be retained where possible to prevent sediment from eroding into water bodies.

- Disturbed areas will be revegetated with native or approved non-invasive seed.

- After construction, improvements will be inspected and maintained to ensure proper function and nominal erosion levels.

- Revegetation work and sites will be inspected to verify adequate growth and contingency measures implemented as necessary.

\section{Vegetation}

Rebuilding a section of BPA's 115-kV Allston-Astoria No. 1 line to 230-kV double circuit design is expected to cause only minor impacts to vegetation because the corridor has been subjected to ongoing vegetation management. In the Wauna Tap to Allston-Astoria No. 1 corridor, however, it would be necessary to remove trees to make way for the new towers and conductors and to establish low-growing plant communities to protect the transmission lines from potential interference. The impact to vegetation in the previously unmanaged corridor would be moderate, but will not affect unusual or unique plant communities or special status plant species.

Mitigation:

- Vehicles will be restricted to access roads as much as practicable.

- Topsoil will be left in roughened and uncompacted condition, except on road shoulders.

- To avoid spreading noxious weeds, vehicles will be washed at established wash stations before entering the project area.

- Disturbance of native plant communities will be limited to the minimum necessary.

- Disturbed areas will be revegetated with native or approved non-invasive seed, with fertilizer and mulch applied as appropriate.

- Ground-disturbing machinery will not be used on steep slopes.

- Only individual tall-growing species will be cut and ground cover of low-growing species such as grasses and shrubs disturbed as little as possible.

- In canyons deeper than 120 feet, only trees tall enough to be within 50 feet of the conductors and capable of growing into the lines will be cut.

- Vegetative buffers will be retained to prevent sediment migration to water bodies.

- Vegetation management practices consistent with BPA's Transmission System Vegetation Management Program EIS (DOE/EIS-0285) will be followed. 


\section{Fish and Wildlife}

Rebuilding a section of BPA's 115-kV Allston-Astoria No. 1 line to 230-kV double circuit design would temporarily disturb resident wildlife, which would adjust to avoid construction activity. Removing trees in the short Wauna Tap to Allston-Astoria No. 1 right-of-way would displace wildlife associated with mid-successional forest habitat. Because the area is near the existing Driscoll Substation, existing natural gas line, access roads, a former rock quarry, and Highway 30 opposite the Wauna industrial area, the additional impact to wildlife is expected to be low. Columbian white-tailed deer, an endangered species, may feed in the project area but will be avoided if present. Coho salmon, a threatened species, inhabit streams crossing the project area but there will be no construction activity in streams. No other sensitive fish and wildlife species would be affected.

Mitigation:

- Construction workers will be informed about guidelines for construction in Columbia whitetailed deer habitat:

1. Drive with caution in the project area during times of limited visibility (e.g., dusk through dawn). If deer are observed, reduce vehicle speed to account for the actions of the visible deer as well as the likelihood that other deer are nearby; and

2. Harassment of deer (such as chasing by dogs, shooting at, or automobile interaction) is prohibited.

- To minimize disturbance to soils and vegetation, vehicle use will be restricted to existing access roads as much as possible, and new structures will be installed as close as possible to existing structure sites.

- To avoid physical disturbance to salmon fry and other fish species during the removal and replacement of the towers and transmission lines, construction vehicles will not ford fishbearing streams at any time, and alternate crossing structures will be used to access both sides of the fish-bearing streams.

- Tree removal will be limited to danger trees.

- Use of herbicides will be consistent with BPA's Transmission System Vegetation Management Program EIS (DOE/EIS-0285).

\section{Water Quality}

Rebuilding a section of BPA's 115-kV Allston-Astoria No. 1 line to 230-kV double circuit design would have little or no effect on water quality. While vegetation removal and soil disturbance could potentially increase soil erosion, sediment deposition into streams is unlikely because the streams are generally located in ravines while construction sites will generally occur on the ridges and higher ground. Undisturbed intervening vegetation should intercept most or all sediments. Riparian vegetation and soils in the ravines would not be disturbed and vehicles would not ford streams. Construction would be avoided near a domestic water supply intake in Graham Creek. 
Risk of impacts to water quality resulting from oil and fuel spills from construction equipment would be low because equipment operation would not be performed near the streams and an SPCC plan would be in place.

Mitigation:

- A project Spill Prevention, Control, and Countermeasures Plan will be kept on the work site at all times. Strategically placed spill response kits will be kept on the site and appropriately stocked. Should a spill occur, spill cleanup operations will begin immediately upon discovery and appropriate regulatory and response parties notified.

- To avoid or minimize chemical contamination of surface waters from mechanized equipment during construction, there will be no refueling, oil/fluid changes, or storage of equipment within 400 feet of any water body or wetland. Mechanized equipment will be inspected daily for leaks, and promptly repaired or replaced if leaking. During the parking and moving of fuel truck/tanks on roads, right-of-ways, and staging areas, precautions will be taken to avoid accidental spills.

- No structures will be located within the Midland Water Association's Drinking Water Protection Area around Graham Creek.

- To avoid physical disturbance to surface water quality during the removal and replacement of the towers and transmission lines, construction vehicles will not ford streams unless dry, and alternate crossing structures will be used to access both sides of wet streams.

- No conductor tensioning sites will be located within 50 feet of streams.

\section{Floodplains and Wetlands}

Rebuilding a section of BPA's 115-kV Allston-Astoria No. 1 line to 230-kV double circuit design would have little or no effect on floodplains or wetlands. The project area includes two wetlands included in the USFWS National Wetland Inventory. Both sites are located between the existing Allston-Astoria No. 1 structures 21/5 and 22/1. Structure 21/5 is approximately 100 feet east of a wetland classified as palustrine emergent semi permanently flooded. Structure 22/1 is approximately 200 feet west of a wetland classified as palustrine emergent seasonally flooded. These wetlands total 0.67 acre within the existing transmission line right of way. No construction would occur near wetlands. Also, no construction would occur in flood zones.

Mitigation:

- No structures or conductor tensioning sites will be located within 50 feet of wetlands.

- Existing wetland areas will be identified on project plans and flagged in the field to ensure they will be avoided by construction activities.

\section{Visual Quality}

Rebuilding a section of BPA's 115-kV Allston-Astoria No. 1 line to 230-kV double circuit design will have little or no effect on the visual quality of the landscape. The visual context of the proposed project is an existing transmission line corridor that includes an adjacent $230-\mathrm{kV}$ double-circuit transmission lines with lattice steel structures. The partial rebuild would simply replace an existing transmission line in an existing transmission corridor. The project area is 
surrounded by a landscape of natural appearing industrial forest with patches of clearcut on mountainous terrain. The surrounding forests will continue to be harvested for timber in a shifting patchwork pattern. As the patchwork shifts, the landscape probably would expose different sections of the transmission line corridor to view. However, the overall nature of the viewshed will remain about the same.

No mitigation is required for visual quality.

\section{Cultural Resources}

Rebuilding a section of BPA's 115-kV Allston-Astoria No. 1 line to 230-kV double circuit design is not likely to affect cultural resources. A review of records found none indicating that cultural resources are exist in the project area. If present, they may have been affected by past construction, operations, and maintenance activities associated with the existing transmission line. However, BPA will confirm absence of cultural resources and, if found, will avoid their disturbance.

Mitigation:

- BPA will survey the construction area for presence of cultural resources. If resources are found, construction site locations will be adjusted as necessary to avoid disturbance.

- If archaeological material is encountered during construction, work at the site will stop and the BPA archaeologist notified. Work will not restart at the site without clearance from the archaeologist.

\section{PUBLIC AVAILABILITY}

This ROD will be distributed to all interested parties and affected persons and agencies. Copies of the BP EIS, BP ROD, the initial July 25, 2003, ROD for the Summit/Westward Project, and additional copies of this ROD are available from BPA's Public Information Center, P.O. Box 12999, Portland, Oregon, 97212. Copies of these documents may also be obtained by using BPA's nationwide toll-free document request line: 1-800-622-4520, or by accessing website www.efw.bpa.gov.

\section{CONCLUSION}

BPA has decided to offer contract terms for interconnection of the Summit/Westward Project into the FCRTS at a point adjacent to CPUD's Wauna Substation. These contracts will include a Generation Interconnection Agreement that provides for interconnection of the Project with the FCRTS, the operation of Summit in the BPA Control Area (including control area services such as generation imbalance service), the maintenance of reliability of the FCRTS and interconnected systems, and a Construction, Operation and Maintenance Agreement that provides for the construction of the interconnection facilities and their operation and maintenance. BPA will also offer a Construction Agreement to CPUD, to allow joint use of about 8 miles of BPA's 115-kV Allston-Astoria No. 1 transmission line right-of-way by CPUD for their new Bradbury-Wauna 230-kV transmission line. 
All practicable means to avoid or minimize environmental harm are identified above and are hereby adopted, to be included as conditions in BPA's Construction Agreement with CPUD. BPA adopts and will undertake, or require the Project to undertake, the mitigations identified in this ROD, including mitigations imposed in the permits and decision documents of the relevant regulatory agencies. BPA contracts providing for integration of power from the Project into the FCRTS at a point adjacent to CPUD's Wauna Substation shall include terms requiring that the Project obtain all required Federal, State, and local permits and approvals for environmental compliance such as air emissions, water, wetlands, wildlife species, cultural/historic resources, and land use before the contract is implemented. These contracts shall also include terms requiring the Project to comply with terms and conditions of all permits issued pertaining to the Project.

As relevant to environmental concerns, this decision to offer contract terms for an optional interconnection of the Summit/Westward Project into the FCRTS is not substantially different than BPA's previous offer for interconnection at Allston Substation. Further, with adoption of these mitigation measures, I find no significant new circumstances or information relevant to environmental concerns bearing on the optional interconnection at a point adjacent to CPUD's Wauna Substation or reconstructing a section of BPA's 115-kV Allston-Astoria No. 1 transmission line from single-circuit $\mathrm{H}$-frame wood-pole design to double-circuit single metal pole design.

Issued in Portland, Oregon.

\begin{tabular}{lc} 
/S/ Stephen J. Wright & Oct. 21, 2004 \\
\hline Stephen J. Wright & Date \\
Administrator and & \\
\multicolumn{2}{c}{ Chief Executive Officer }
\end{tabular}

